\title{
A dureza do fazer. A práxis na urbanística de Saturnino de Brito a partir do seu plano de saneamento para a cidade de Santos (1905-1910)
}

\author{
Sidney Piochi Bernardini \\ Arquiteto e Urbanista pela Universidade Católica de Santos, doutor \\ em Arquitetura e Urbanismo pela Faculdade de Arquitetura e \\ Urbanismo - FAU-USP, docente do Departamento de Arquitetura \\ e Construção da Faculdade de Engenharia Civil, Arquitetura \\ Urbanismo da UNICAMP, Avenida Abert Einstein, 951, Campinas, \\ SP, CEP 13083-852, (19) 3521-2389, sidpiochi@fec.unicamp.br
}

\begin{abstract}
Resumo
O artigo pretende discutir a atuação do engenheiro sanitarista Saturnino de Brito durante o período que chefiou a Comissão de Saneamento de Santos do governo estadual de São Paulo, entre 1905 e 1910. Brito foi incumbido de realizar as obras de saneamento daquela cidade que, por longos anos, havia sido assolada por epidemias de febre amarela, dizimando parte de sua população. Ao enfrentar uma série de obstáculos e dificuldades que foram interpostos durante o processo de execução destas obras, a conduta do engenheiro demonstrou a sua habilidade em combinar conhecimentos variados para lidar com as problemáticas intrínsecas ao plano desenvolvido.
\end{abstract}

Palavras-chave: Saturnino de Brito, urbanismo moderno, saneamento.

\section{processo de execução das obras de saneamento em Santos}

A atuação do engenheiro Saturnino de Brito nas obras de saneamento da cidade de Santos, entre 1905 e 1910, é pontuada por polêmicas e controvérsias, demonstrando, por um lado, a capacidade do engenheiro em lidar com conflitos e obstáculos de várias ordens, superando-os progressivamente para atingir os objetivos na realização das obras e, por outro, o ambiente político que envolvia a realização de reformas urbanas naquele momento de desenvolvimento das atividades imobiliárias lucrativas com a implantação de novos loteamentos e criação de novas atividades urbanas. Brito se envolveu com, pelo menos, três episódios conflituosos conhecidos durante a sua permanência como Chefe da Comissão de Saneamento de São Paulo para os serviços de Santos. O primeiro, ocorrido logo que assumiu, dizia respeito aos prejuízos deixados pelo Chefe antecessor, José Pereira Rebouças, nas obras de instalação de um emissário que lançaria os esgotos ao mar. O segundo se deu na realização dos canais de drenagem, na intermediação com a empresa empreiteira responsável pelas obras, sob comando do engenheiro Augusto Carlos da Silva Telles que abandonou o contrato sem concluí-las. O terceiro ocorreu em meio à entrega do plano urbanístico final elaborado por Brito à Câmara Municipal da cidade, posteriormente rechaçado pelos vereadores locais por ferir interesses dos proprietários. Este último episódio foi o estopim para que o engenheiro pedisse demissão da Comissão de Saneamento e fosse desenvolver o plano de saneamento de Recife, a partir de 1910. Estes episódios, entretanto, não foram isolados e nem pontuais, demonstrando o embate entre as várias forças que gravitavam em torno destas intervenções que mudariam radicalmente a paisagem da cidade de Santos.

Quando assumiu a Comissão de Saneamento do Estado em 1905, Brito já conhecia os problemas de Santos e já os havia estudado em 1898. As soluções propostas por Brito foram provavelmente discutidas 


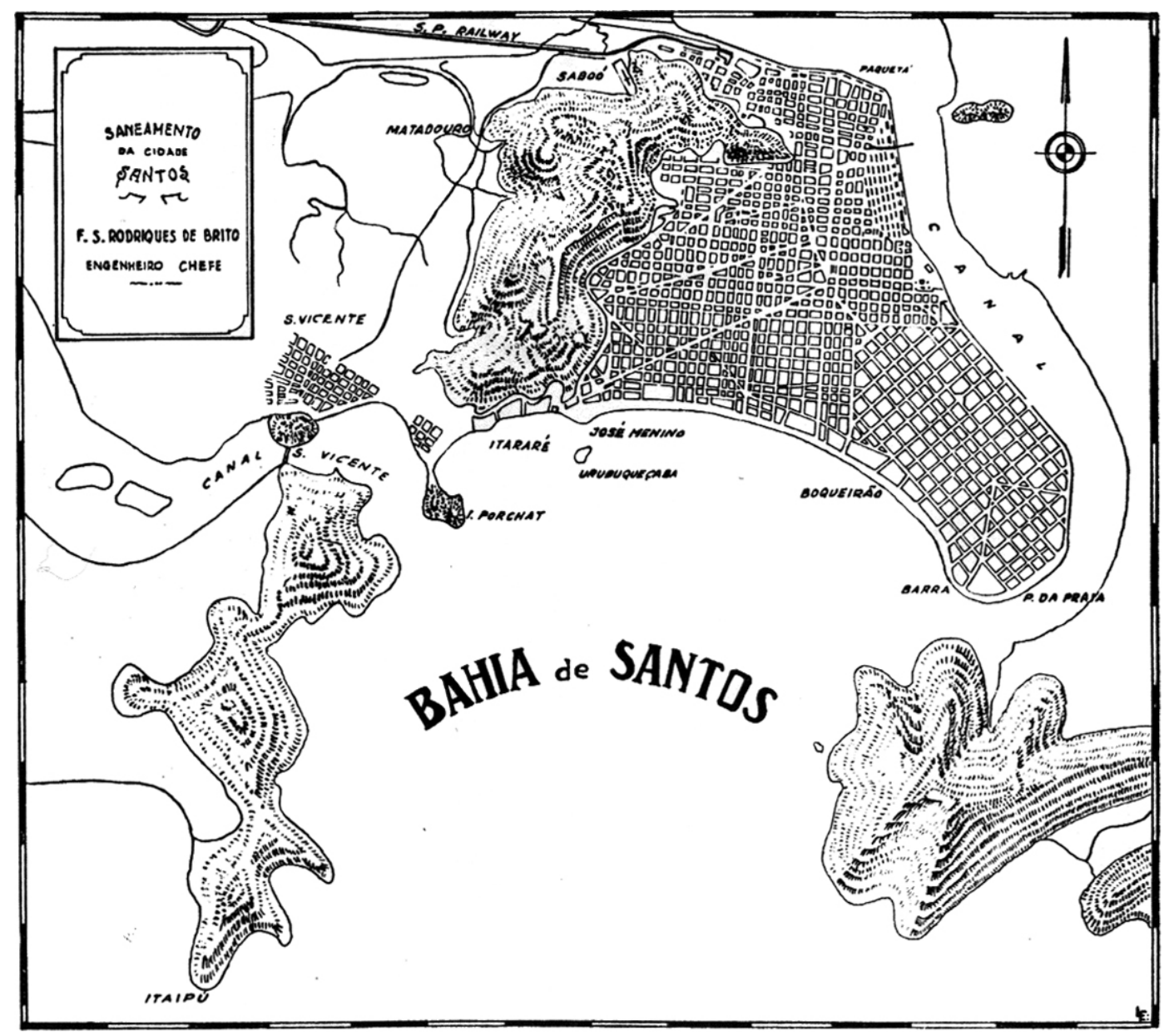

Figura 1: Planta de Santos relativa aos estudos de Saturnino de Brito de 1898. Fonte: Brito, 1943. com o engenheiro Theodoro Sampaio, que fora chefe da Repartição de Águas e Esgotos do Estado entre 1898 e 1903 (COSTA, 2003), já que havia comentários em seu diário a respeito de um projeto para Santos. Saturnino estava elaborando o projeto de saneamento de Petrópolis, de onde escreveu este primeiro esboço para a cidade de Santos. Já havia, dois anos antes, elaborado o projeto de arruamento, saneamento e melhoramentos do novo arrabalde de Vitória, projeto que comprova a excepcionalidade de Brito como o precursor do urbanismo moderno no Brasil ao propor um traçado urbano inovador (ANDRADE, 1992).

Na introdução desta primeira proposta, Saturnino já observava as interferências políticas na condução dos trabalhos para o saneamento de Santos. Mal sabia o quanto isso se tornaria evidente alguns anos depois. De fato, ele próprio seria vítima de mudanças que tinham como objetivo claro a rearticulação de forças, com a entrada de Antônio Francisco de Paula Souza no comando da Secretaria de Agricultura, em abril de 1898, e a dissolução da antiga Comissão de Saneamento, vinculada àquela, para a qual havia formulado a proposta.

Saturnino de Brito admitia não seguir nenhum dos projetos elaborados. Podia estar se referindo ao plano que o engenheiro norte-americano Estevan A. Fuertes havia elaborado para aquela cidade em 1892 através de uma contratação com o governo estadual (BERNARDINI, 2012), que certamente conhecia e foi a base para o seu próprio plano e o do engenheiro José Brant de Carvalho, que desenvolveu um plano de arruamento para a expansão urbana de Santos no ano de 1896 (SANTOS, 1897), discutindo-os, anos depois, após sofrer ataques, da Câmara Municipal, ao seu próprio plano. Denunciava, assim como 
todos os outros engenheiros que desenvolveram propostas para Santos, a separação parcial do sistema então existente entre esgotos e águas pluviais. Já em 1898, Brito enfatizava a importância das obras de drenagem, ignoradas pelo governo após a sua saída da Comissão de Saneamento naquele ano. Ele falava dos arrabaldes e da contribuição que teriam no âmbito do projeto da rede de drenagem, pressupondo a construção de uma nova rede viária que extrapolaria a cidade existente. Neste sentido, seu estudo abrangia até mesmo os morros da cidade, cuja solução de drenagem era imprescindível para a ocupação dos terrenos úmidos do mencionado "novo arrabalde". Foi com esta abrangência que Brito, ainda em 1898, calculou todo o sistema de drenagem projetado (BRITO, 1943).

Saturnino já se preocupava, naquele ano, com a construção de uma nova paisagem e definia critérios para estender a cidade, divergindo do que a Câmara Municipal havia aprovado para esta extensão. Esboçava as bases para o projeto que executaria a partir de 1905. Em seu relatório de 1898, estabeleceu uma relação entre águas pluviais dos arrabaldes e dessecamento dos terrenos úmidos, pensando no novo arruamento para a cidade. Ao se referir ao plano da Câmara, elaborado por José Brant de Carvalho, afirmava que deveria ser substituído por outro, incluindo uma série de ruas atravessando em diagonal as que cortavam em ângulos retos. Estas diagonais encurtariam as distâncias, mantendo a boa circulação do ar e trazendo novas belezas à "progressista cidade de Santos". Complementava que nestas avenidas seriam estabelecidas os emissários, tronco e ramais, ocupando a parte central e deixando alamedas laterais arborizadas. Foi ele, portanto, que pensou neste novo arruamento, utilizando-se da experiência que vivera, alguns anos antes, na sua proposta do novo arrabalde para Vitória (PRADO, 2000, CASAGRANDE, 2011).

A maturidade técnica e urbanística do conhecimento de Brito consolidou-se até 1905 quando conseguiu tornar-se chefe da Comissão de Saneamento. Uma série de elementos conjugar-se-iam para que ele pudesse efetivamente aplicar o seu pleno conhecimento traduzido, naquilo que podemos chamar de teoria do urbanismo de Saturnino de Brito. Já em 1898, Brito falava da utilização do concreto armado nos canais, mas a essência do relatório era uma sequência ininterrupta de cálculos matemáticos onde mostrava a relação entre vazão e contribuição das bacias - um estudo sistemático de engenharia.

Na parte relativa aos esgotos, apresentou o que ele chamava de sistemas estáticos (as fossas) e dinâmicos, que ele dividiu em sistema unitário, separador ou de canalização distinta e o sistema pneumático. Defendia o sistema pneumático para Santos, que funcionaria através das máquinas de aspiração e compressão. Dizia que as próprias máquinas pneumáticas poderiam ser apropriadas para a condução dos produtos de esgoto ao campo da depuração, libertando o porto de carga infecta. Dizia ainda que a planta da cidade e de seus arrabaldes favorecia o projeto do sistema pneumático irradial. Acreditava ser possível utilizar os produtos do esgoto para irrigação, pensando em uma depuração pelo solo. Saturnino não explicou as razões científicas de sua opção, mas citou os nomes de Emílio Ribas e Theodoro Bayma, o que sugere uma aproximação com a teoria microbiana (ANDRADE, 1992).

Embora citasse tais cientistas e demonstrasse um conhecimento prático daquilo que propunham, Brito não fez menções ao plano Fuertes. Seria proposital? Equivocadamente, o engenheiro dizia que o engenheiro norte-americano adotara um sistema estático para Vila Mathias e Vila Macuco. Em seu plano, estes bairros faziam parte do segundo distrito e teriam seus esgotos ejetados pelo sistema shone, que Brito adotaria em 1905. Saturnino discordava do emprego da alvenaria para os esgotos, que havia sido aceita por Fuertes, desde que executada de forma correta e com total impermeabilidade. 0 fato é que o alto preço da canalização por tubos metálicos e a inadequação da utilização da alvenaria acabaram conduzindo-o a utilizar os tubos de concreto armado em 1905.

Não só o plano de Fuertes deixou de ser considerado por Saturnino de Brito, mas também as intervenções municipais que estavam sendo realizadas com a abertura das avenidas Conselheiro Nébias e Ana Costa. Mais do que isso, Brito não mencionaria as obras de canalização do rio dos Soldados na área central - todas realizações que certamente utilizou como insumos para seu plano. De certa forma, a própria municipalidade tinha iniciado a construção efetiva de um plano para esta retificação que posteriormente levaria o nome de Brito. Já em 1900, a municipalidade esforçava-se por fazer 
o dessecamento das áreas inundáveis da ilha e o engenheiro da Câmara, José Gonçalves de Oliveira, demonstrava esta preocupação e, mais do que isso, compreendia bem o problema, sabendo que a municipalidade não tinha recursos para executar obras de grande vulto como as estabelecidas pelo plano Fuertes (SANTOS, 1900).

Independentemente de todas as ideias, propostas e intervenções até então realizadas pelo município e pelo Estado, o ano de 1905 foi um marco na transformação da paisagem de Santos, contrapondose à lentidão com que o governo estadual havia tratado o saneamento daquela cidade até então. 0 seu empenho em executar as obras não era mais uma resposta apenas ao problema das epidemias, como pode parecer, pois estas já estavam praticamente controladas. As intervenções da polícia sanitária e o conhecimento científico já bastante divulgado, com a descoberta do vetor da febre amarela, amenizaram o discurso vigente do cuidado com a doença através de intervenções físicas. Ficava a cargo dos engenheiros, e isto é sintomático no caso de Brito, apresentar um outro discurso que se voltava para o embelezamento (BERNARDINI, 2009).

Em 1905, Saturnino efetivamente iniciou os trabalhos de saneamento em Santos sem explicitar a existência de um novo plano. Dizia apenas que este, agora organizado e em execução era o desenvolvimento daquilo que esboçara nos anos de 1898, 1902 e 1903. Certamente, estes últimos já eram ideias que Saturnino amadurecia enquanto realizava os trabalhos de saneamento de Campos (ANDRADE, 1992), ao mesmo tempo em que desenvolvia um plano geral de abastecimento de água para São Paulo. Este plano que apresentava, que dizia ser ao mesmo tempo uma consolidação de seus trabalhos anteriores, consistia basicamente em três grupos de obras:

Esgotos sanitários: coleta, elevação e emissão da contribuição de despejos por meio da divisão da área em pequenos distritos; descarga in natura em pleno mar ou descarga após depuração no estuário ou barra; reforma completa;

Reforma completa das instalações domiciliares;

Esgotos pluviais: circunvalação da montanha por meio de valas ou sarjetas interceptoras e de caixas de sedimentação; galerias pluviais descarregando diretamente no estuário; canais de drenagem, com avenidas marginais cortando as planícies dos subúrbios e abertos de mar a mar de modo que se dê a renovação das águas.

A vinda de Brito para a Comissão de Saneamento fol caracterizada, por um lado pela aplicação imediata das ideias já desenvolvidas, utilizando-se de suas propostas anteriores e transformando-as, a partir de 1905, em obras. Além disso, partia do princípio da expansão para os arrabaldes, sem que adotasse maiores explicações para esta expansão, dada como natural e certa, na programação de suas obras. Já em seu primeiro ano, continuou as obras do coletor geral iniciadas pelo engenheiro José Pereira Rebouças, complementadas por uma rede nova, organizada por um sistema de distribuição distrital, pensando a descarga das águas servidas na Ilha Porchat, com depuração prévia, além dos serviços complementares das obras de saneamento do ribeirão dos Soldados, que já haviam sido começados pela municipalidade. A Comissão criou ainda uma fábrica de blocos de cimento e de tubos de areia e cimento para a construção de poços de inspeção. No ano seguinte, Brito começaria a fazer todo o detalhamento dos projetos e, para isso, fez o levantamento de uma rigorosa planta topográfica da cidade, com o projeto dos novos arruamentos. Dizia que a cidade de Santos deveria ter a sua rede de esgotos executada conforme o seu desenvolvimento, previsto e projetado e que não deveria ser alterado pela Câmara Municipal ou pelos interessados nos arruamentos de seus terrenos.

Ao mesmo tempo, Saturnino começava, de forma cuidadosa, a interferir definitivamente na vida política local. Era o início de uma aproximação com a cidade que o levaria, anos mais tarde, a ser questionado pelos grupos políticos locais. Até 1912, Brito construiria boas relações com os atores locais, ganhando adeptos voluntários à execução do plano. Embora Brito só encaminhasse a planta da cidade à Câmara Municipal de Santos em 1910, já em 1906, apresentava uma lei que a previa. As boas relações que ainda mantinha com a Câmara, mesmo que ocasionais, permitiram-lhe, portanto, nestes primeiros anos de trabalho, desenvolver as obras. Os terrenos levantados estavam sendo cedidos gratuitamente pelos proprietários. Entre estes, apareciam os nomes de Catarina Ablas, Luiza Macuco, João Antunes dos Santos, João da 

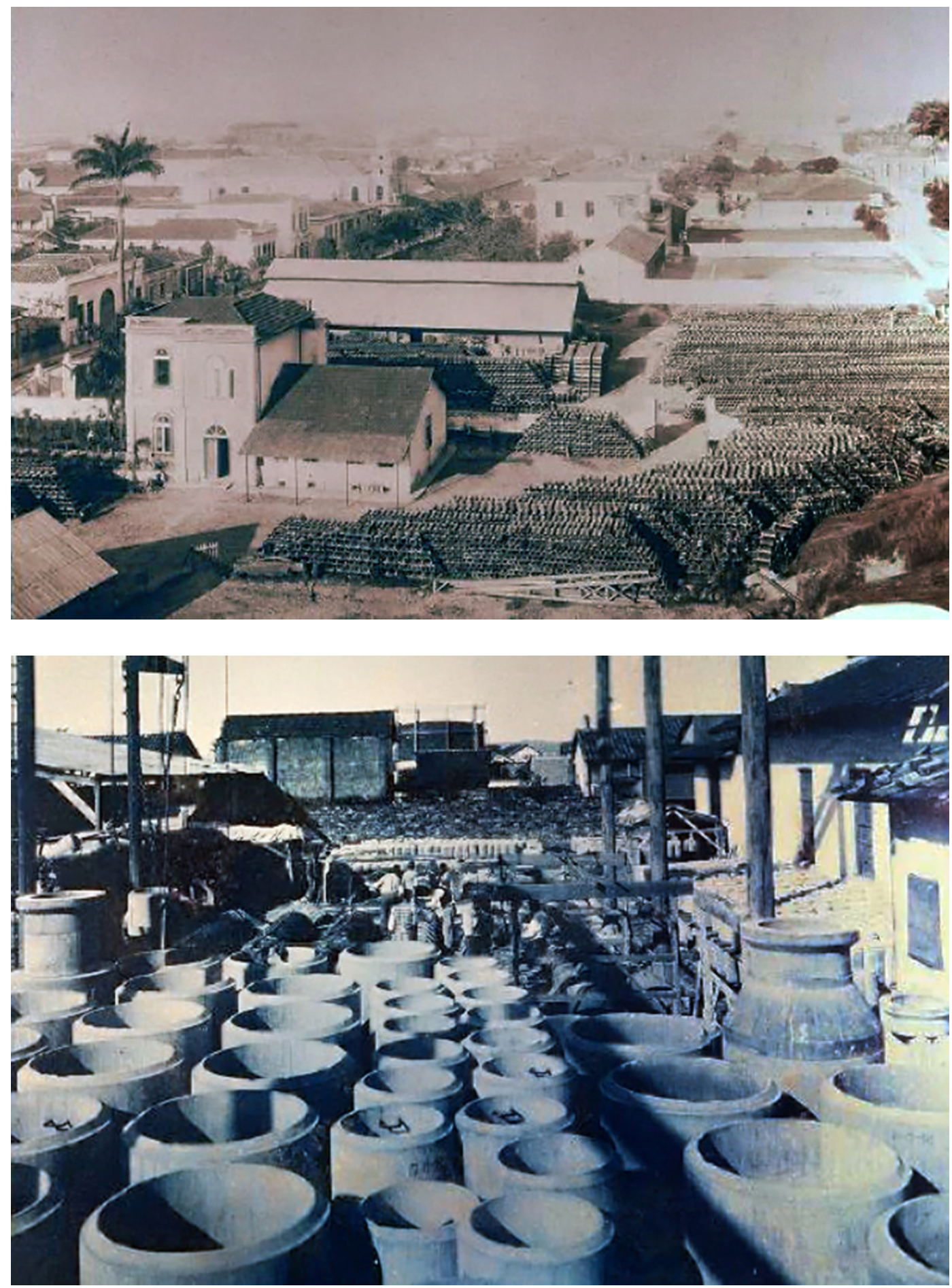

Figura 2: Fábrica de tubos de cimento criada para a execução da rede de esgotos da cidade de Santos. Fonte: Acervo iconográfico da Faculdade de Arquitetura e Urbanismo da Universidade Católica de Santos. 


\begin{tabular}{|l|l|l|l|}
\hline Canais e galerias & 1907 & 1908 & 1909 \\
\hline Canal 1 (Soldados ao morro do Jabaquara) & 1.360 & 3.674 & 2.165 \\
\hline Canal 2 (morro do Jabaquara à praia) & & & 2.273 \\
\hline Canal 3 (Brás Cubas) & 390 & 412 & 741 \\
\hline Canal 7 (Jabaquara) & & 55 & 55 \\
\hline Canal 9 (Usina) & 278 & 278 & 278 \\
\hline Galeria 3 (24 de Maio) & & & 160 \\
\hline Galeria 4 (Itororó) & & & 385 \\
\hline Trechos de galerias, bueiros, coletores (manilhas) & & & 1866 \\
\hline Descarga de extravasão dos esgotos & & & 36 \\
\hline Total & $\mathbf{2 0 2 8}$ & $\mathbf{4 4 1 9}$ & $\mathbf{7 2 7 9}$ \\
\hline
\end{tabular}

Tabela 1: Extensão dos canais e galerias de drenagem de Santos (em metros lineares). Fonte: BRITO, Francisco Saturnino Rodrigues de. Relatório dos trabalhos de 1905-1906 em Santos in BRASIL - Ministério da Educação e Saúde. Obras completas de Saturnino de Brito - Projetos e Relatórios - Saneamento de Santos. Rio de Janeiro, Instituto Nacional do Livro / Imprensa Nacional, 1943 - vol. VII.
Costa Ferreira e Belmiro Ribeiro, que seria, a partir de 1912, prefeito de Santos e um dos principais envolvidos na polêmica entre a Câmara Municipal e Brito na aprovação do seu plano. Belmiro Ribeiro, que impediria a aprovação da planta na Câmara, cedia em 1906, os terrenos para a execução dos canais de drenagem e as extensas avenidas laterais. Todos estes nomes, aliás eram os de futuros loteadores interessados na expansão urbana que naturalmente valorizaria seus terrenos (BRITO, 1915).

Em 1906, Saturnino ainda não estava executando as novas ligações domiciliares e os consertos nas obras antigas, pois dizia que só poderiam ser executadas segundo os princípios sanitários rigorosos, depois de aprovado um regulamento e de disposto o material apropriado. Para isso, a Comissão organizaria um cadastro dos esgotos domiciliares do qual constariam todos os detalhes das instalações e contaria com a Câmara, que não daria nenhuma licença para construção de prédios sem que as plantas estivessem aprovadas pela Comissão. Começava a se delinear um conjunto de regras que, desta vez, traduziam-se em leis e formas de controle aplicados pelo Poder local. Brito chegou a escrever estes regulamentos, sabendo que esta aplicação seria feita pelo município e que permitiriam a execução completa do plano, como a desapropriação e a contribuição de melhorias, além de outras que tratavam dos quarteirões salubres e vielas particulares (BRITO, 1915).

Se por um lado Brito desenvolvia um plano que indicava o crescimento da cidade, com novos desenhos de ocupação, como um modelo teórico a ser seguido, impunha a execução das obras de forma concreta, desenhando também todos os detalhes construtivos que permitiam prosseguir na expansão que se realizava, com uma rapidez nunca vista na cidade. Em 1906, concluía 815,37 metros de canal (no rio dos Soldados até Braz (ubas) e, em 1907, os canais e galerias já tinham 2.028 metros a extensão, ainda concentrados na área central da cidade. No relatório de 1909, declarava que o canal dois estava quase concluído e o de número três, até então abandonado, estava também bastante adiantado para o lado da barra de Santos. Quanto aos esgotos, em 1907, a rede já tinha 26.013 metros, chegando a 66.804 metros em 1909.

Com a evolução das obras dos canais, em 1909, a expansão já chegava ao mar, na barra, e também ultrapassava os limites do município. Paralelamente, o engenheiro desenvolvia estudos para o despejo e depuração dos esgotos de Santos e São Vicente. Enquanto Fuertes indicava uma solução na própria cidade, sugerindo os despejos em Outeirinhos, na região portuária, Brito levava os esgotos para local 

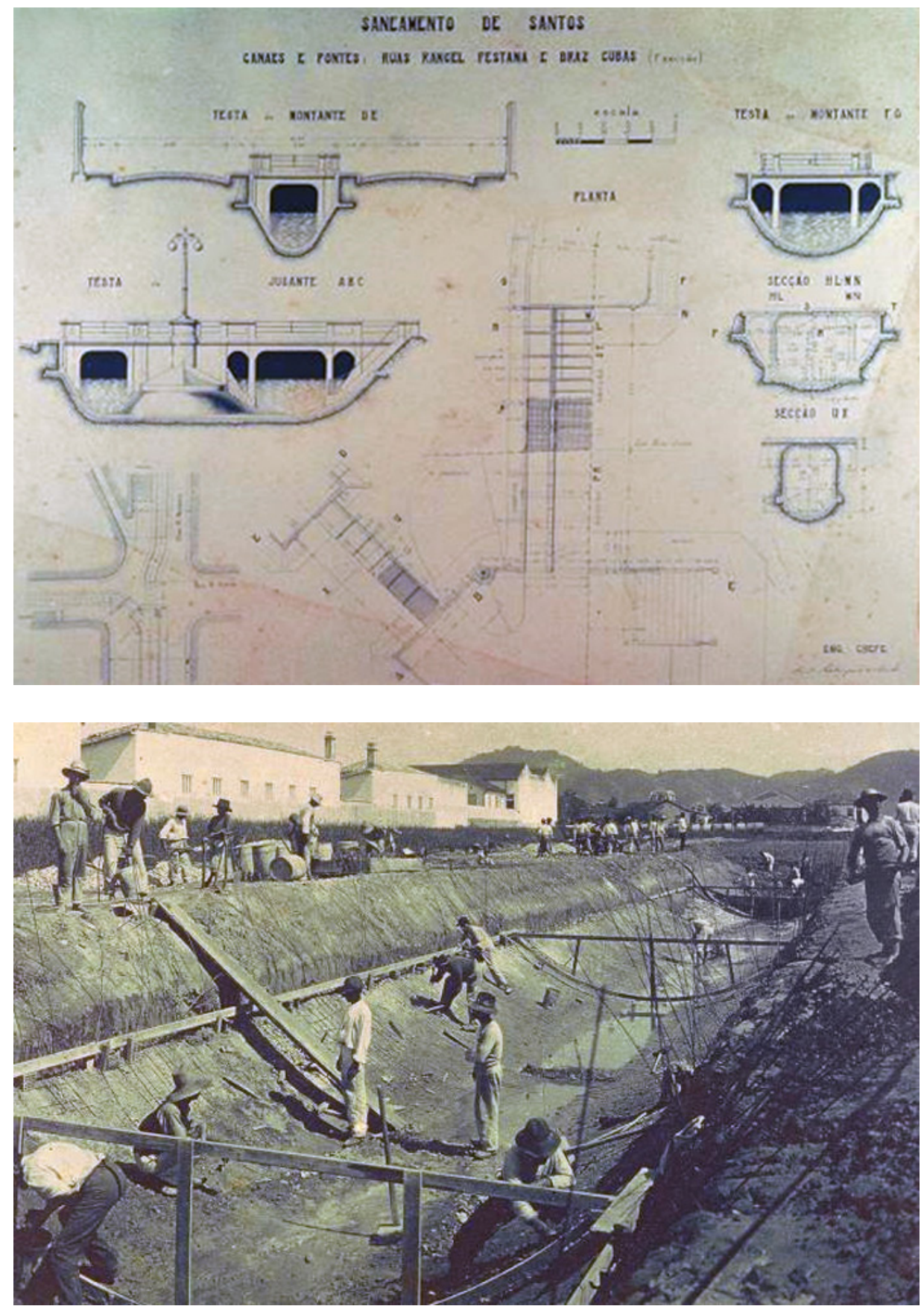

Figura 3: Projetos dos canais e pontes da Rua Rangel Pestana e Braz Cubas e construção dos canais de drenagem. Fonte: Acervo iconográfico da Faculdade de Arquitetura e Urbanismo da Universidade Católica de Santos. 
afastado da cidade, que já tinha sido indicado por Theodoro Sampaio. Esta questão levou a uma discussão dentro do governo, em 1908, que teve a última palavra na decisão do melhor local para os despejos, orientada pelos custos.

Ele era favorável a instalar mecanismos de depuração dos esgotos, além de utilizar os esgotos para o aproveitamento agrícola, embora não descartasse o lançamento in natura ao mar para cidades com baixa densidade. Apresentou ao governo, portanto, duas alternativas. A primeira, que já vinha sendo estudada, era lançá-los na praia de Itararé, utilizando terrenos próximos para realizar o aproveitamento agrícola do efluente depurado, vinculando a este projeto, a instalação do Horto Botânico que seria irrigado com a água depurada. A segunda, era fazer a descarga in natura na ponta de Itaipu, com a previsão de uma futura depuração completa ou parcial e, até mesmo, a irrigação com o efluente depurado. As duas seriam realizadas, mas, embora a primeira tivesse a preferência de Saturnino e fosse iniciada antes mesmo de se cogitar a segunda, a última é que seria escolhida pelo governo, em 1908, após a mudança de gestão, com a saída de Jorge Tibiriçá e entrada de Albuquerque Lins na presidência do Estado. Em 1909, os 1.500 metros na ponta de Itaipu já estavam construídos

A dimensão política regia todo o processo de implementação das obras, ainda que houvesse um grande esforço de Brito em conduzi-lo de forma isenta e com apuro técnico. O engenheiro não discutia determinadas decisões, mas era rigoroso em relação à gestão financeira, sabendo que disto dependia o sucesso de seu plano. Os engenheiros João Pereira Ferraz e Augusto Carlos da Silva Telles, envolvidos em uma polêmica com Theodoro Sampaio, em 1902, na ocasião da contratação das obras para a instalação da rede de esgotos e que culminou na saída deste último da chefia da Repartição de Águas e Esgotos do Estado (COSTA, 2003), voltaram a se envolver nas obras conduzidas por Saturnino, que tinha conhecimento do conflito. Além destes, também a Companhia Mecânica Importadora fornecia os tubos de ferro fundido para os emissários e as manilhas cerâmicas, por um contrato de 1907.

A polêmica com Silva Telles, a partir de 1906, é mais uma página da história controvertida do planejamento em Santos. Vejamos como Saturnino de Brito descreveu a evolução dos serviços entre 1905 e 1908, no seu Relatório, logo após a mudança do governo naquele ano. Dividiu-a em quatro fases. Na primeira, o governo não cogitava fazer o esgotamento pluvial das ruas, nem das montanhas e nem dos canais de drenagem superficial da planície. Na segunda, sob sua direção, a Comissão iniciou estudos aproveitando aqueles já existentes (1898) resultando na planta, com a expansão da cidade em toda a planície entre o sopé da montanha, o estuário e a barra, e na rede de esgotos, para o serviço atual e futuro. O governo resolveu que fossem aproveitados os 2.197 metros de coletor Rebouças, restringindo a liberdade do novo projeto e a escolha para o local dos despejos, que teria de ser feito na extremidade do coletor em Itararé. A utilização do sistema distrital reduziu os custos iniciais. Nesta segunda fase ainda, foram iniciados os trabalhos por administração dos esgotos e dos canais, cuja execução foi organizada em pequenas empreitadas, excluindo os serviços de maior responsabilidade. O regime por administração durou de agosto de 1905 a maio de 1906, passando a partir desta data a ser executado por empreitada até agosto de 1907, caracterizando a 3 a fase. Após a rescisão deste contrato de empreitada (com Augusto Carlos da Silva Telles), houve a normalização dos serviços por administração e tarefas, da rede de esgotos, em 1907 e, da rede de canais, em 1908. Em agosto de 1907, a Comissão rescindiu o contrato com Telles, estabelecendo outro contrato apenas para as obras dos canais, finalizado em fevereiro de 1908 (BRITO, 1943).

Estas fases apresentadas por Saturnino demonstram como foram executados os serviços de saneamento em Santos, por ele dirigidos com a maior seriedade, mas, ao mesmo tempo, permitem esclarecer a nova polêmica que se instalou com a contratação do engenheiro Augusto Carlos da Silva Telles. Assim se pronunciava Brito em relação àquela contratação:

"Este regime durou, para os esgotos sanitários, de agosto de 1905 até maio de 1906, mas, conforme disse no relatório de 1906, não foi possível dar aos trabalhos o normal andamento e nem colher dai o desejado e necessário proveito, visto ter o vosso antecessor (o Sr. Dr. Carlos Botelho) resolvido os adjudicar logo após o início dos trabalhos". (BRITO, 1943: 334) 
Brito deixava transparecer insatisfação com a decisão do Secretário da Agricultura pela empreitada. Também deixava claro que Carlos Botelho, então Secretário de Agricultura, Serviços e Obras Públicas, pasta responsável pelas obras de Santos, pretendia contratar estes serviços, atrapalhando o andamento dos trabalhos e promovendo a polêmica que resultou em uma incessante troca de ofícios entre Saturnino de Brito e Silva Telles com os vários secretários da Agricultura. Aparentemente, a desavença entre estes engenheiros foi o embrião do grande debate com a Câmara de Santos quando encaminhou a sua planta para a aprovação dos vereadores. Esta polêmica inteiramente relatada na publicação $\underline{A}$ planta de

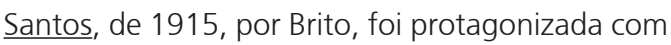
o seu filho, Francisco Teixeira da Silva Telles (FICHER, 2005), então diretor de obras da Prefeitura Municipal de Santos. Na própria publicação, Brito destacava:

"Penso que a má vontade do Sr. Dr. Telles contra a Comissão de Saneamento remonta ao período de 1905 a 1907, antes de conhecermo-nos pessoalmente; era s. s. distinto estudante da Escola Politécnica, e teria certamente ouvido queixas contra a atitude da Comissão, no modo pelo qual esta entendeu que devia zelar os interesses do estado, tendo sempre o aplauso dos mais eminentes responsáveis pelas coisas públicas do mesmo estado. Devo ainda dizer que os atos da Comissão foram sempre tão corretos que os próprios interessados em uma empreitada (e alguns distintos parentes destes), embora prejudicados nas suas pretensões nunca nos recusaram fazer justiça sempre me dispensaram as atenções e gentilezas que o Sr. Dr. Telles entendeu de me negar. Não quero ir além, neste assunto delicado, salvo se o Sr. Dr. Telles me forçar a mudar de resolução". (BRITO, 1915: 78)

Embora Brito não se referisse explicitamente ao pai, deixava claro que a atitude desrespeitosa do engenheiro municipal advinha dos acontecimentos gerados na ocasião do contrato por empreitada de 1906. Reciprocamente, a ira de Brito contra Francisco Telles advinha de sua indignação ao perder a disputa contra Augusto Silva Telles, o pai, na ocasião da empreitada das obras. Brito revelava seu relacionamento mal resolvido com a família Telles. Para Francisco Silva Telles, interessava desenvolver os pequenos planos de loteamentos na cidade, junto com Roberto Simonsen e o prefeito Belmiro Ribeiro, com os quais montaria, em 1912, a Companhia
Construtora de Santos. Respaldado por Belmiro Ribeiro, exerceria todo o seu poder de articulação para recusar a planta de Brito naquele ano. As boas relações com a cidade e a Câmara, que permitiram a desapropriação dos terrenos para a execução do plano nos primeiros anos, transformar-se-iam entre 1905 e 1910, em uma relação de conflito que impediria o governo estadual e Saturnino de atuarem na complementação do plano proposto.

De fato, Francisco Silva Telles herdava a vocação empreendedora de seu pai, engenheiro formado pela Escola Politécnica do Rio de Janeiro e Professor da Escola Politécnica de São Paulo, desde 1897. Telles envolveu-se em vários trabalhos polêmicos. Já naquele ano havia participado de uma concorrência para a iluminação elétrica da capital, que envolveria capitais franceses, sem dar resultados (SÃO PAULO, 1898). O governo estadual tentou prorrogar o prazo da concorrência para viabilizar a implementação da iluminação por eletricidade. Sem lograr êxito, Silva Telles, alguns anos depois, envolveuse com a concorrência das obras de esgoto em Santos, demonstrando sua versatilidade como empreendedor, em busca de um filão lucrativo para investir. Em 1907, mesmo ano em que rescindia o contrato das obras de Santos, o engenheiro publicava Melhoramentos de São Paulo, um opúsculo com propostas para a capital paulista. O texto servia para divulgar o conjunto de obras e melhoramentos que idealizava para as cidades brasileiras, a exemplo de São Paulo, demonstrando a possibilidade de contrair empréstimos para esta realização (SILVA TELLES, 1907).

A polêmica de Silva Telles nas obras de Santos iniciouse em 14 de janeiro de 1908, quando enviou um Ofício ao Secretário da Agricultura da época, Carlos Botelho, reclamando dos prejuízos que estava tendo na empreitada e solicitando a rescisão contratual, alegando que os preços estabelecidos no contrato por empreitada eram impraticáveis. Além disso, Silva Telles acusava a Comissão, presidida por Brito, de manipular os valores para a remuneração de seus serviços. Mas a acusação em relação aos valores permaneceu sem esclarecimentos de Saturnino de Brito, que concordava totalmente com a rescisão. Em 24 de janeiro, o Secretário encaminhou Ofício a Saturnino avisando-o do pedido de Silva Telles e determinando a suspensão dos trabalhos. Seguindo a determinação do Secretário, mas adiantando-se em 
relação à rescisão, Brito encaminhou Ofício a Telles em 28 de janeiro, confirmando a rescisão contratual ainda em agosto de 1907 e solicitando que os trabalhos em andamento fossem regularizados até o dia $1^{\circ}$ de fevereiro, data prevista para a suspensão das obras por empreitada e medição final das mesmas. Silva Telles, ofendido, respondeu a Brito dizendo que sabia da suspensão dos trabalhos, mas que o governo não havia ainda resolvido sobre tal rescisão, que só a ele competia resolver. Em 31 de janeiro, Brito encaminha novo Ofício a Silva Telles confirmando a suspensão dos trabalhos e responsabilizando-o pela demora no cumprimento de suas ordens. Em 05 de fevereiro, o Secretário ordenava a rescisão do contrato.

As tratativas tumultuadas entre Saturnino de Brito e Silva Telles continuariam. De 1 a 5 de fevereiro, antes que o Secretário determinasse a rescisão contratual, Brito e o representante de Silva Telles, Florisbello Leivas trocaram várias cartas, este dizendo que na contingência de opor-se à pretensão da Comissão, enquanto não recebesse ordens, não atenderia à solicitação daquele.

Na ocasião da rescisão do contrato, o governo nomeou dois engenheiros, João Caetano Alvares e Augusto Ramos, ambos da Secretaria de Agricultura, para examinarem, junto com a contadoria, as alegações de Silva Telles e dar um parecer sobre o caso. Em 6 de abril, os engenheiros apresentavam o relatório concluindo que Telles havia tido prejuízo e devia ser indenizado. Curiosamente, até mesmo os custos com uma Ação que movera na ocasião da concorrência das obras de esgoto de 1902, apareceram nas contas de indenização. Recebendoas, o governo fez alguns descontos, mas decidiu pelo pagamento total de 160:212\$950 a Silva Telles, contrariando Saturnino de Brito. Em 2 de maio de 1908, Brito encaminhava Ofício ao novo Secretário da Agricultura Antônio Cândido Rodrigues, apenas um dia após a sua posse Indignado, questionava os valores e as decisões quanto à indenização que deveria ser paga.

Brito, ao fazer todos estes questionamentos, levava ao conhecimento do novo Secretário as irregularidades que acusava. Para o engenheiro, a Comissão de investigação, formada por engenheiros comissionados em cargos de confiança, tinha se pronunciado ilicitamente, até mesmo ao substituir folhas da medição que Saturnino fora obrigado a entregar-Ihe. Eugênio Lefevre, então diretor geral da Secretaria, apresentava as mesmas explicações às do Ofício que mandava pagar as custas à Telles. Obrigado a fazer o pagamento, Brito perguntava de que dotação tiraria o recurso do pagamento, obtendo como resposta que não havia outro meio senão fazer correr a despesa por conta do saneamento de Santos, ou seja do recurso ordinário das obras.

Não contente, após receber a quantia definida, Silva Telles encaminhou outro Ofício, em 26 de maio, ao Secretário de Agricultura, pedindo a restituição de cauções retidas pela execução das obras de saneamento de Santos. Solicitava não só as cauções de $10 \%$ que tinham sido descontadas das folhas de medição que importavam em Rs. 37:068\$738, mas também a caução inicial no valor de Rs. 30:000\$000 em apólices do estado. Silva Telles, além de garantir as indenizações, reivindicava receber as quantias caucionadas sem executar as obras restantes estabelecidas no contrato antes de tê-lo rescindido, sob protestos de Brito que passou a condenar os serviços de Silva Telles nos relatórios que encaminhava ao Secretário, desqualificando-os e chamando as obras de "aleatórias". Somente em 1908, Brito apresentaria planilhas demonstrando as diferenças de preços entre os serviços realizados por administração e aqueles empreitados:

"O empreiteiro propondo os preços da Comissão, como estavam organizados, incorreu na imprevidência de não distinguir um processo do outro. Verificado isto, mui difícil se tornou chegar a um acordo, quer porque assim sucede com obras de natureza fundamentalmente aleatória, quer porque o empreiteiro nunca deu aos serviços o aparelhamento e o desenvolvimento necessários, ao mesmo tempo que mantinha mui onerosa administração; produziu em média, 30:000\$000 por mês e as suas despesas de administração em Santos representavam, como é sabido, cerca de $20 \%$ das folhas de medição mensal, absorvendo o lucro razoável". (BRITO, 1943: 158)

Em outro relatório, destacava a vantagem de retornar as obras ao regime de administração. Através de um quadro comparava o custo efetivo por administração e aquele se as obras continuassem sendo feitas por empreitada. Somente após 1908, as obras transcorreriam de forma tranquila, obras estas que aguardaram, desde 1892, para serem realizadas. 
No ano anterior, o governo inaugurava o primeiro canal (canal 1 - retificação do rio dos Soldados) na extensão de 2 quilômetros, com as duas avenidas laterais arborizadas. A inauguração empolgou a cidade com uma grande festa, na qual compareceram os representantes do poder paulista, senadores e deputados estaduais, junto a Saturnino de Brito e Augusto da Silva Telles, que em meio à conturbada disputa de bastidores, subiram no mesmo palanque.

\section{Quatro aspectos da modernidade urbanística brasileira a partir de Saturnino de Brito}

Saturnino de Brito, apesar de rigoroso em relação às contas públicas e rígido quanto aos seus princípios, teve grande habilidade política em conduzir o plano de saneamento de Santos, tomando-o com uma obstinação e perfeccionismo que excluía todos que, de alguma forma, não tinham a mesma determinação que ele. Esta habilidade permitiu a concretização do plano, ainda que parcial. A execução dos canais de drenagem, imprimindo uma nova paisagem à cidade era apenas uma parte do plano proposto, conforme entregue à Câmara santista, em 1910, um ano após a sua saída da Comissão de Saneamento, por ter sido convidado a trabalhar no plano de saneamento de Recife. No entanto, estes canais foram estruturadores para o desenho da cidade, tornando-a legível e conferindo até hoje importante referência urbanística e simbólica de orientação aos habitantes. A implementação do plano de Brito foi determinante para a história do urbanismo no Brasil, como bem demonstrou ANDRADE (1992).

A entrega da planta de Santos, em 1910, na Câmara Municipal de Santos, marcava a transição entre uma reflexão abrangente sobre o desenho da cidade como forma unitária dotada de lógica interna, para outro momento, marcado pela fragmentação e individualização dos investimentos urbanos em loteamentos e bairros, como aconteceria no caso da Vila Belmiro, primeiro loteamento concebido por Francisco Silva Telles, Belmiro Ribeiro e Roberto Simonsen, aprovado após a grande polêmica de Saturnino com a Câmara Municipal. Esta última não era mais do que o ajuste político com uma tendência que se constituía a partir de uma fração da burguesia paulista que pretendia reproduzir seu capital em investimentos urbanos, na implantação de infraestrutura e na abertura de novos arruamentos. A planta de Santos de 1910 representa, portanto, mais do que um ato político de aproximação entre governo estadual e municipal, devido à grande habilidade de Brito, o resultado de uma série de inovações na construção do planejamento e implementação do urbanismo moderno. Saturnino consolidava uma atuação da prática da engenharia, na transição do século XIX para o XX, que em Santos pode ser percebida por meio das várias propostas e planos concebidos desde os primeiros anos da República.

Esta maioridade foi marcada por quatro características principais, consolidadas por Brito em seu trabalho. A primeira, diz respeito à introdução efetiva da discussão sobre a boa forma e estética urbanas, como produtos artísticos do pensamento e da atividade intelectual do urbanista. ANDRADE (1992) desenvolveu o seu trabalho em torno desta tese principal ao estudar a atuação de Brito, não só em Santos, mas em outras cidades brasileiras. Não é objetivo deste trabalho voltar a esta temática, mas é importante destacar o quanto o pensamento de Brito marcou o ideário urbanístico neste período, orientado pela construção da cidade como paisagem, ressoando as tradições pinturescas da Londres dos séculos XVIII e XIX e sua evolução para as mais variadas experiências francesas e norte-americanas de desenho, induzindo o artista a um olhar disciplinado que organizava a paisagem como fragmento e nela dissolvia a arquitetura (ANDRADE, 1992: 43). Como se viu claramente na evolução de sua postura em relação ao urbanismo, Brito foi realmente inovador ao colocar tridimensionalidade nas proposições que adotava, dimensão que aparecia de forma ainda muito tímida nas intervenções anteriores e que, no plano de Fuertes, foi omitida.

De qualquer forma, as teorias discutidas - mesmo filtradas como foi o caso de "A construção das cidades segundo seus princípios artísticos" de Camilo Sitte traduzido para o francês por Camille Martin (ANDRADE, 1992) - evidenciaram um período em que buscou-se pensar a forma da cidade e de sua paisagem. A relação entre edificações e traçado das ruas elucida a aproximação com Camilo Sitte, mas a ideia do subúrbio com jardins poderia estar associada a alguns poucos princípios das cidadesjardins inglesas, considerando, além disso, o variado conjunto de planos nacionais e internacionais que serviram de referência para Brito, como o plano de Washington e Barcelona. De que forma Camilo 
Figura 4: A planta de Santos de 1910. Fonte: BRITO, 1915
Sitte, que tratava do traçado das cidades antigas e medievais, análises aplicáveis restritamente às cidades existentes e suas áreas centrais, poderiam ressoar em Brito para seu plano de expansão? A aplicação da ideia da cidade como corpo são e belo é uma entrada para a explicação.

A segunda questão diz respeito ao desenvolvimento da técnica aplicada à construção das cidades. O conhecimento científico então introduzido lançaria bases para a evolução da engenharia no século XX, Em Brito, há a preocupação com o apuro técnico. Nas revistas de engenharia, já da primeira década do século XX, cada vez mais surgiam experimentações e aplicações da Matemática e da Física aos seus projetos e obras. Brito realizava intervenções que eram fruto de uma extensa gama de estudos, ensaios e cálculos matemáticos de grande complexidade. Os modelos esquemáticos dos canais e os cálculos de sua geometria são provas desta afirmação.

A aproximação entre os engenheiros e médicos sanitaristas, embora continuasse a existir por anos após o desenvolvimento da microbiologia (CAMPOS, 2002), seria ainda mais caracterizada por contribuições especializadas de cada profissão. A evolução da engenharia sanitarista como campo especializado do saber levaria à aplicação deste conhecimento em obras de saneamento de grande porte. Embora presente também em Fuertes, este conhecimento desenvolvera-se com mais profundidade em Brito. Naquele, havia um envolvimento com as ciências

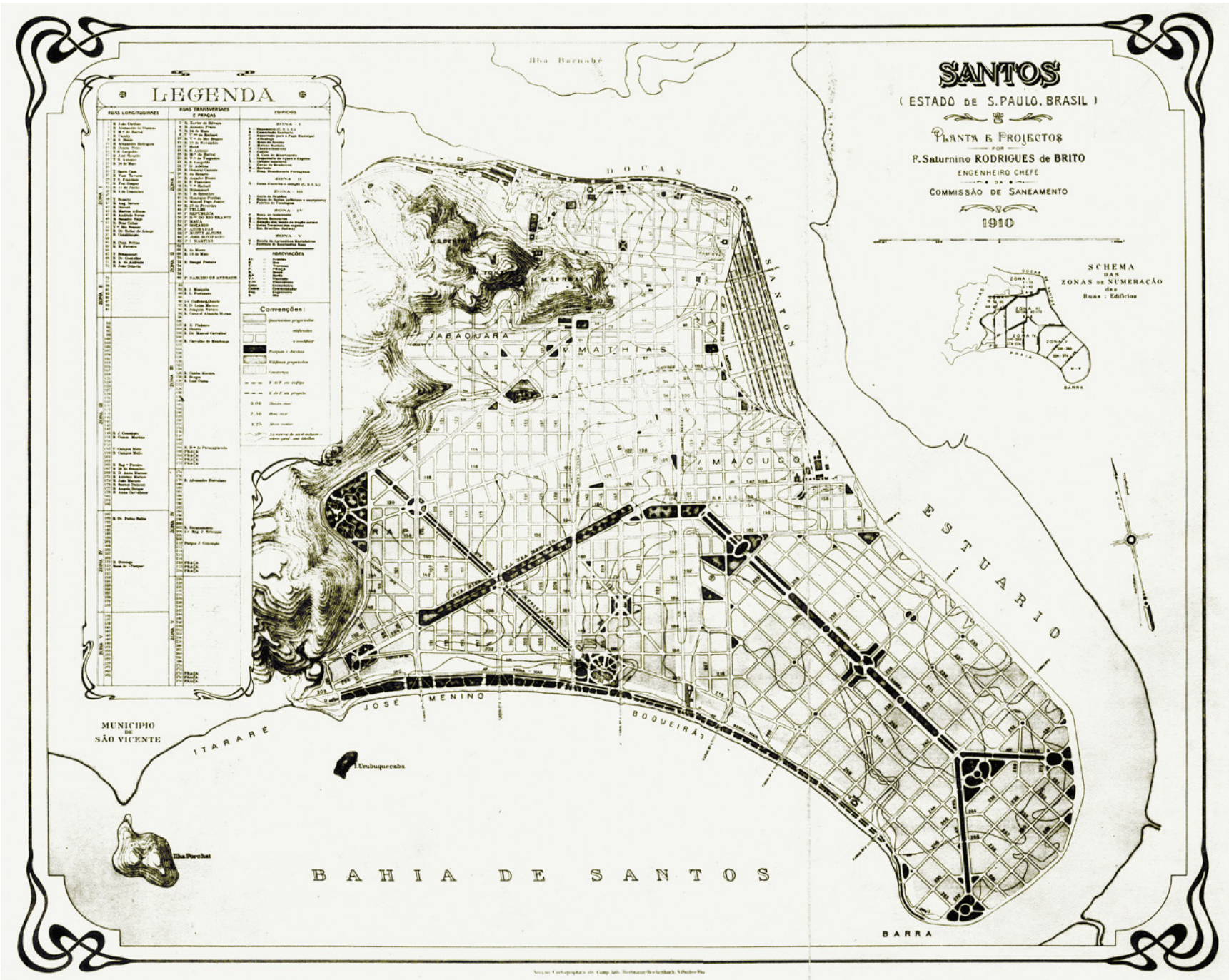


biomédicas, na relação entre doenças e medidas profiláticas. Brito sugeriria uma forma de atuação em que a engenharia, embora comparada com a medicina, teria uma função específica:

"Para trazer uma cidade atormentada por endemias e explosões epidêmicas basta o mau serviço sanitário do seu aparelhamento aferente e eferente, especialmente este. Com efeito, será preciso tratar da casa como se trata do homem; apenas a engenharia substitui a medicina, ou melhor, aparece a função do técnico higienista. Já não se cuida só de impedir que as impurezas expedidas se acumulem em torno do indivíduo, ou em torno da casa: é preciso cuidar da canalização eferente da casa como cuida o médico do aparelho intestinal do indivíduo". (BRITO, 1943: 44)

Além disso, a utilização dos materiais e o conhecimento de suas propriedades e resistências permitiu que a tecnologia da construção tivesse mais êxito e eficiência. Em pouco mais de quatro anos, Brito executaria toda a extensão do canal um e alguns trechos dos outros canais, além do coletor geral de esgotos e da rede complementar. A utilização do concreto armado para os tubos coletores era uma novidade que Brito teve a sensibilidade de desenvolver, observando as condicionantes apropriadas para o projeto. Não somente o cimento trouxe eficiência às obras, mas o desenvolvimento de diversos materiais e sistemas construtivos como, por exemplo, o processo de assentamento das manilhas cerâmicas de esgoto.

Aliado ao aspecto técnico está o aspecto financeiro, terceiro ponto que assinalamos nesta análise. O financiamento das obras de Brito só foi possível através de um rígido planejamento e acompanhamento dos custos e gastos, por meio de um novo sistema adotado por ele. O cuidado financeiro revelava uma opção de atuação política que consolidava o meio urbano como atrativo importante de investimentos. Na estrutura de uma burguesia predominantemente agrária, a oscilação dos investimentos indicava a presença de uma fração desta burguesia associada ao grande capital cafeeiro, interessada em aplicar recursos em obras urbanas. Com Brito estas pretensões puderam concretizar-se por meio de uma engenhosa organização dos trabalhos. As controvérsias com Rebouças e Silva Telles davam amostras do que seria a prática das grandes obras urbanas de engenharia, durante o século $X X$. Coberto pelos interesses firmados entre empresas fornecedoras e contratos de empreitada, Brito pôde conduzir as obras até um limite estabelecido pelos interesses desta burguesia, quando os investimentos passaram a ser direcionados, de outra forma, como nos pequenos projetos de melhoramentos posteriores e na implantação de energia elétrica, extensão do transporte urbano e de loteamentos. De sua planta, aproveitariam apenas o esqueleto. Mas, ainda assim, como um bom positivista, Brito acreditava ser possível aliar a técnica à economia, como determinante na evolução da cidade brasileira, ao falar das obras em 1909, quando deixou a Comissão de Saneamento:

"Ver-se-á que, apesar de todos os imprevistos, como sejam a empreitada das obras, no seu início, contra a minha opinião, a rescisão onerosa e singular dos contratos, e, finalmente a necessidade de demorar a execução para não sobrecarregar o tesouro, ver-se-á que, apesar de todas estas circunstâncias onerosas, imprevistas, o orçamento inicial se mantém sem notável alteração global. Este será o proveitoso ensinamento para a execução das nossas obras públicas e a Comissão de Saneamento, tendo cumprido o seu dever, se sente mais feliz de o divulgar do que mesmo de ver reconhecido o sucesso da técnica dos trabalhos, porque esse sucesso, para generalizar em proveitosos benefícios sanitários, depende da demonstração da exequibilidade econômica dos projetos sanitários. Deixemos aos inconscientes a vanglória dos seus projetos, alguns bem extravagantes e contraproducentes, executados por preços elevadíssimos, ao mesmo tempo que desprezam a engenharia indígena no seu meticuloso labor de acertar na técnica modesta e com boa administração". (BRITO, 1943: 404)

O quarto e último aspecto a ser destacado é a constituição das leis urbanas. A criação do Código Sanitário estadual e do Código de Posturas Municipal identifica-se com a ideia de uma materialização de uma imagem de cidade. No caso de Brito, a criação de leis específicas tinha um caráter, eminentemente jurídico, de instrumento para a obtenção e construção do plano, imprimindo mais rapidez nesta execução, como era o caso das leis de desapropriação e contribuição de melhorias. Tomando por base outras já existentes, Brito criou leis inovadoras porque considerava a valorização imobiliária a partir do melhoramento implantado. De início, sua proposta já distinguia dois níveis de desapropriação: os casos de utilidade pública imediata, relativos aos planos 
que seriam imediatamente executados após as desapropriações e os casos de utilidade pública remota para os planos de melhoramentos futuros, sem desapropriação imediata. Nos casos remotos, o poder público poderia ou não expropriar os terrenos, garantindo áreas para a implantação de, pelo menos, as vielas sanitárias. Estava garantida aí a disponibilização dos terrenos para a expansão urbana. O sucesso das desapropriações estava nas garantias dos proprietários. Para isso, Brito estabeleceu um quadro em que apresentava os ônus e os proveitos do proprietário nas avaliações dos imóveis na ocasião das desapropriações.

Por outro lado, Brito buscava reorganizar a prática da vida coletiva dos habitantes. A sua fundamentação estava na própria noção que tinha da moralidade e sua relação com os aspectos higiênicos, como elementos indispensáveis à saúde pública. Era, portanto, favorável à instituição de uma ordem que fosse capaz de neutralizar os conflitos externos e penetrar em cada célula construtiva, disciplinando as condutas individuais, sendo contrário às atitudes policialescas e ofensivas que não consideravam a evolução da vida coletiva e o aprendizado da cidadania. Nesta linha, restringia-se a adotar uma legislação que instrumentalizasse um controle do poder público, principalmente como forma de implementar o plano e possibilitar o funcionamento dos sistemas adotados. Este era o espírito da Lei Municipal n 288 de 27 de novembro de 1907, que Brito criara e levara à Câmara Municipal para aprovação. Esta lei era um dos primeiros regulamentos que instituíam o setor de aprovação de obras. Exigia que as plantas antes de aprovadas fossem submetidas à Comissão de Saneamento para verificação da adequação em relação as obras de esgotos.

Havia, nestes regulamentos a criação de um modelo urbanístico pautado pela salubridade, complementar ao sistema de saneamento implantado. Brito introduzia uma relação estreita entre o desenho e a lei, com o desenho dos quarteirões salubres, as ruas, ruas particulares e vielas sanitárias assim como em outros projetos de lei que escreveu. Os esquemas projetados por Saturnino representavam o desenvolvimento de um modelo que poderia ser aplicado em qualquer lugar.

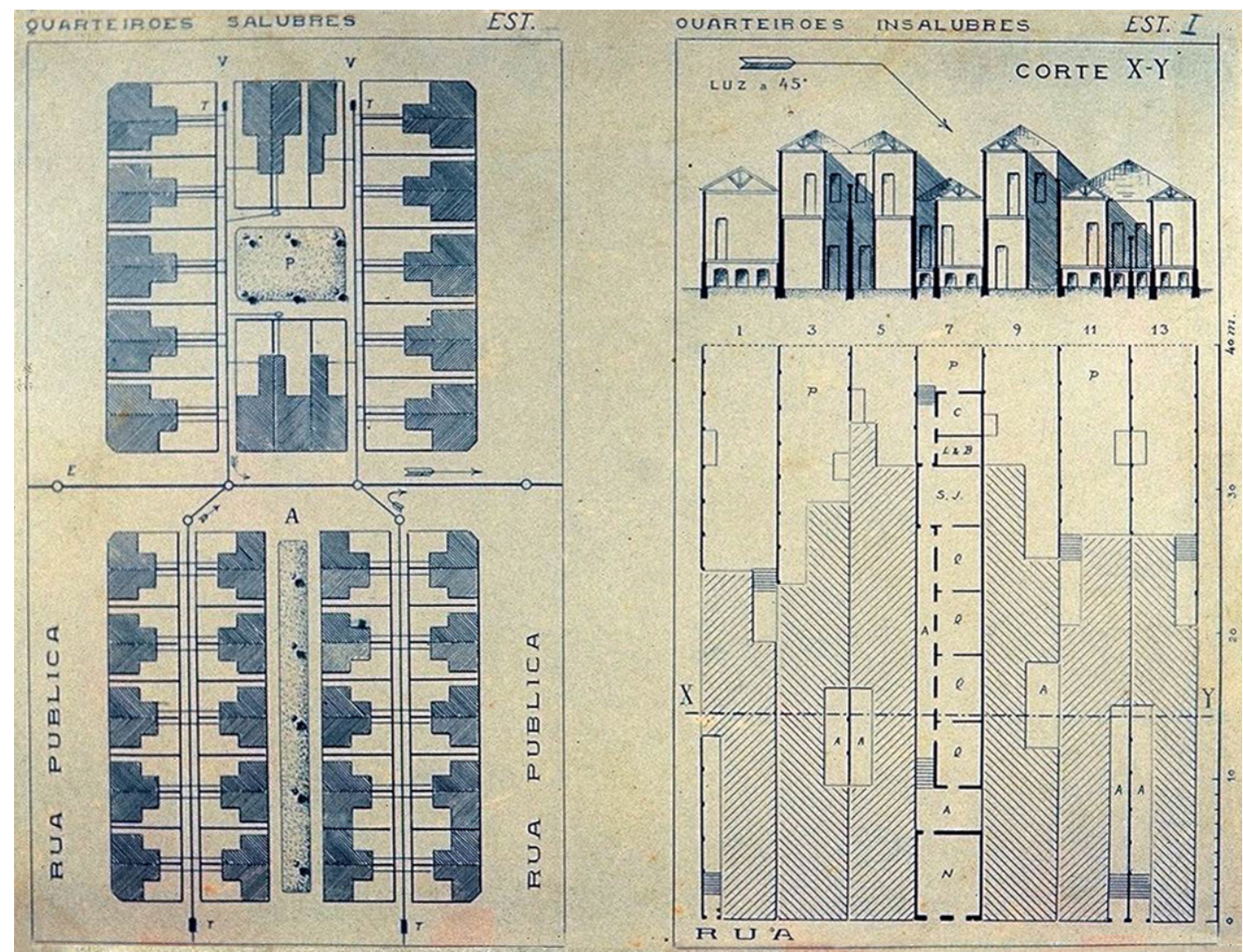


Fazia parte deste regulamento a criação de vias particulares que eram espaços internos semi públicos para facilitar o lançamento de esgotos, além de possibilitar a entrada de ar para a higienização das casas. Após a execução total das redes de esgoto e drenagem, era necessário, segundo Brito, criar regulamentos, como uma espécie de manual de uso para um novo tipo de habitação. O pensamento de Brito consolidaria o marco legal como forma de produção de espaço. Nas suas formulações para Santos, veríamos o amadurecimento do urbanismo como campo de atuação específica e a legislação seria, daí para frente, utilizada para ordenar a cidade e gerar seus novos contornos.

\section{Considerações finais}

A passagem de Saturnino de Brito pela Comissão de Saneamento do Estado de São Paulo frutificouse em uma das mais importantes experiências da urbanística moderna no Brasil: o plano de saneamento da cidade de Santos. Embora não totalmente implantado, conforme propunha o engenheiro no seu desenho original, é possível perceber claramente como o seu traçado orientou o desenvolvimento posterior da cidade. Esta capacidade de Brito em executar obras de engenharia complexas que permitiram a expansão da cidade em terrenos pantanosos e lodacentos merece destaque e é isto que este artigo buscou trazer. Envolvido em uma sequência de controvérsias e conflitos pontuados por um conjunto amplo de indivíduos e grupos interessados nos rumos do desenvolvimento urbano e nas possibilidades especulativas que este poderia promover, Brito mostrou-se capaz de materializar, em parte, os pressupostos de uma urbanística que se internacionalizava com os tratados e escritos de arquitetos como Camilo Sitte e Raymond Unwin. Mas além destes, Brito foi capaz de pensar e conceber uma urbanística própria, esta que aliava conhecimentos da estética, da técnica e do Direito, no esforço de instituir os mecanismos necessários para trabalhar a dura realidade social brasileira, que, decerto, conhecia

As experiências concretas realizadas por Brito entre 1905 e 1910 mostram que a efetivação das intervenções no campo do urbanismo no Brasil já não passava, naquele momento, apenas pela adoção de modelos e traçados, como pode parecer à primeira vista ao se visualizar o belo desenho da planta de
Santos, mas já derivava, fundamentalmente, da articulação dos vários campos de saber e, do duro enfrentamento das questões políticas que gravitavam em torno das belas soluções.

\section{Referências bibliográficas}

ANDRADE, Carlos Roberto Monteiro de (1992). A peste e o plano: o urbanismo sanitarista de Saturnino de Brito. Dissertação de Mestrado, São Paulo, FAU USP.

BERNARDINI, Sidney Piochi (2006). Os planos da cidade: as políticas de intervenção urbana em Santos - de Estevan Fuertes a Saturnino de Brito (1892 - 1910). São Carlos, RIMA - FAPESP.

BERNARDINI, Sidney Piochi (2009). Construindo infraestruturas, planejando territórios. A Secretaria de Agricultura, Comércio e Obras Públicas do governo estadual paulista (1892 - 1926). Tese de doutorado, São Paulo, FAU USP.

(2012). Epidemia e saneamento. O engenheiro Estevan A. Fuertes e seu plano sanitarista para a cidade de santos (1892-1895). Arquitextos (São Paulo), v. 144.

BRITO, Francisco Saturnino de (1915). A planta de Santos. São Paulo, Typ. Brazil de Rothischild \& Co.

CASAGRANDE, Braz (2011). Novo arrabalde: conservação e ocupação urbana na concepção do projeto de expansão urbana da cidade de Vitória. Dissertação de Mestrado, São Paulo, FAU USP.

Relatório dos trabalhos de 1905-1906 em Santos in BRASIL - Ministério da Educação e Saúde (1943). Obras completas de Saturnino de Brito Projetos e Relatórios - Saneamento de Santos. Rio de Janeiro, Instituto Nacional do Livro / Imprensa Nacional, v. VII.

CAMPOS, Cristina (2002). São Paulo pela lente da higiene. As propostas de Geraldo Horácio de Paula Souza para a cidade (1925 - 1945). São Carlos, RIMA - FAPESP.

COSTA, Luiz Augusto Maia (2003). O ideário urbano paulista na virada do século. O engenheiro Theodoro Sampaio e as questões territoriais modernas (1886 - 1903). São Carlos, RIMA - FAPESP.

FICHER, Sylvia (2005). Os arquitetos da POLI. Ensino e profissão em São Paulo. São Paulo, EDUSP.

PRADO, Michele Monteiro (2000). Modernização das cidades brasileiras: o projeto de um novo arrabalde para Vitória. SHCU 1990 - Seminário de História da Cidade e do Urbanismo. v. 6, n. 3.

SANTOS (município). Câmara Municipal e Intendência (1897). Relatório apresentado à Câmara Municipal de Santos em sessão de 7 de janeiro de 1897 por Antonio Iguatemy Martins - Presidente da Câmara Municipal e Narciso de Andrade - Intendente Municipal. São Paulo,Typ. a Vapor Carlos Gerke e Cia.

(1900). Câmara Municipal e Intendência. Relatório apresentado à Câmara Municipal de Santos por seu Presidente José Carneiro Bastos e Intendente Adolpho Vaz Guimarães em 7 de janeiro de 1900. Santos, Typ. da Cidade de Santos. 
SÃO PAULO (Estado). Secretaria de Estado dos Negócios da Agricultura, Comércio e Obras Públicas de São Paulo. Relatório de 1897 apresentado ao Dr. Francisco de Assis Peixoto Gomide, vice-residente do Estado pelo Dr. Firmiano M. Pinto, Secretário dos Negócios da Agricultura, Comércio e Obras Públicas. São Paulo, Typ a Vapor Espindola, Siqueira e Comp., 1898.

(1909). Secretaria dos Negócios da Agricultura, Comércio e Obras Públicas de São Paulo. Relatório apresentado Ao Dr. M. J. Albuquerque Lins - Presidente do Estado pelo Dr. Antonio Cândido Rodrigues - Secretário de Agricultura, 1908. São Paulo, Typ. Brazil de Rothschild \& Co..

SITTE, Camilo (1992). A construção das cidades segundo seus princípios artísticos. São Paulo, Ática.

TELLES, Augusto Carlos da Silva (1907). Melhoramentos de São Paulo. São Paulo, Escolas Profissionais Salesianas. 